\title{
O USO DE TECNOLOGIAS SOCIAIS HÍDRICAS NA CONVIVÊNCIA COM O SEMIÁRIDO: O CASO DA COMUNIDADE ÁGUAS BELAS, NAZAREZINHO - PB
}

\section{ARTIGO ORIGINAL}

BRAGA, Jailson Lira ${ }^{1}$

SILVA, Everton Vieira da ${ }^{2}$

QUEIROZ, Jânesson Gomes ${ }^{3}$

LEITE, Michael Douglas Sousa ${ }^{4}$

BELCHIOR, Verônica Cristian Soares de ${ }^{5}$

1 Pós-Graduado em Meio Ambiente e Desenvolvimento no Semiárido pela Universidade Federal de Campina Grande- UFCG, Graduado em Geografia - UFCG. 2 Orientador. Doutor e Mestre em Química Orgânica pela Universidade Federal da Paraíba com ênfase em Aditivos Naturais e Alimentos, Especialista em Ensino de Química, Práticas Assertivas da Educação Profissional Integrada à Educação de Jovens e Adultos - com Ênfase em Didática, Engenharia de Segurança do Trabalho, MBA em Gestão Empreendedora e Inovação.

3 Mestre em Planejamento e Dinâmicas Territoriais no Semiárido pela UERN, Especialista em Ciências Ambientais pelo ISEC, Especialista em Educação Ambiental e Geografia do Semiárido pelo IFRN e Graduado em Geografia pela UFCG.

${ }^{4}$ Mestrando em Sistemas Agroindústrias - UFCG, Pós-Graduado em Docência do Ensino Superior, Graduado em Administração - UFCG.

${ }^{5}$ Mestranda em Sistemas Agroindústrias - UFCG, Pós-Graduada em Ciências Políticas da Educação, Graduada em Ciências Econômicas. 
LACERDA, Wendell de Almeida ${ }^{6}$

LAVOR, Leudiane Holanda ${ }^{7}$

BRAGA, Jailson Lira. Et al. O uso de tecnologias sociais hídricas na convivência com o semiárido: O caso da comunidade Águas Belas, Nazarezinho - PB. Revista Científica Multidisciplinar Núcleo do Conhecimento. Ano 06, Ed. 01, Vol. 01, pp. 105122. Janeiro de 2021. ISSN: 2448-0959, Link de acesso: https://www.nucleodoconhecimento.com.br/meio-ambiente/comunidadeaquas-belas

\section{RESUMO}

Nos últimos tempos o Governo Federal em parceria com várias entidades de cunho não-governamentais vem trabalhando alternativas convencionais de mitigação dos efeitos da escassez hídrica no semiárido através da implantação de tecnologias sociais hídricas, as quais representam uma mudança de paradigma no campo do desenvolvimento humano no Semiárido brasileiro. O presente estudo objetivou identificar aspectos de melhorias na vida das famílias beneficiadas com as tecnologias sociais hídricas de convivência com o semiárido na comunidade Águas Belas, localizada no Município de Nazarezinho - PB. A pesquisa trata-se de um estudo de caso com fusão em levantamentos bibliográficos e documentais na associação dos moradores da comunidade de Águas Belas na cidade de Nazarezinho - PB. Os resultados mostraram que os recursos investidos na comunidade possibilitaram, dentre tantas melhorias, a democratização do acesso à água, cuja é utilizada de diferentes formas, como para beber, para a dessedentação animal, bem como para a produção ecológica de alimentos, a exemplo de hortaliças e legumes. Logo, as

${ }_{6}^{6}$ Mestre em Sistemas Agroindústrias - UFCG, MBA Auditoria Contábil - FIP, Especialista em Psicopedagogia - FIP, Graduado em Administração.

7 Mestranda em Sistemas Agroindústrias - UFCG, Pós-Graduada em Gestão Social (FAMETRO), Graduada em Pedagogia (UECE). 
tecnologias hídricas de convivência com o semiárido têm desempenhado um importante papel no campo da segurança hídrica e alimentar, assim proporcionando bem-estar aos moradores da comunidade Águas Belas. No entanto, essas tecnologias por si só não resolvem todos os problemas que afetam a comunidade estudada e o Semiárido como um todo, sendo necessárias outras políticas públicas complementares para que se alcance melhorias mais significativas.

Palavras-Chave: Acesso à água, cisternas, escassez hídrica, semiárido brasileiro, sustentabilidade.

\section{INTRODUÇÃO}

Grande parte dos diagnósticos e proposições sobre o Semiárido brasileiro tem como referência a imagem historicamente construída sobre um espaço-problema caracterizado pela terra, pela seca e pela miséria. Por meio deste estereótipo social criado em relação à seca enquanto território problema vem sendo intensificado com base em pelo menos cinco estruturas consolidadas: literatura, mídia, música, religião e tratados científicos. São praticamente as mesmas que servem para explicar os problemas socioeconômicos da região semiárida como consequência da seca. Esse pensamento criado de forma espontânea ou não é utilizado como mecanismo de manobra política devido a disseminação sólidas e a aceitação social do problema (CASTRO, 2001; MALVEZZI, 2007; ALBUQUERQUE JÚNIOR, 2009).

A região semiárida ainda é caracterizada pelas profundas marcas da exclusão social provocadas principalmente pelo elevado índice de concentração fundiária. Por muito tempo se atribuiu os problemas da região às características físicas, especialmente ao clima. Esse pensamento construído no imaginário social, formado na consciência das pessoas, não é o resultado exclusivo dos efeitos do clima atrelados à manifestação do fenômeno da seca. Na verdade, trata-se de uma imagem criada pelas pessoas, a qual reflete uma região improdutiva, miserável e inóspita, dando-Ihe uma configuração negativa (ALBUQUERQUE JÚNIOR, 2009; BAPTISTA; CAMPOS, 2013). 
Segundo Lima (2013) e loris (2013), ao longo da história prevaleceu o entendimento de que o Semiárido fosse um espaço marcado pela homogeneidade regional, tanto para as características físicas e ambientais como as socioeconômicas e culturais, se sobrepuseram conjuntamente com o determinismo geográfico que atribui ao clima às causas da problemática socioambiental existente.

Conforme Scheneider (2004) por muito tempo o Semiárido foi tratado como região hostil, um território com poucas oportunidades de desenvolvimento e ambiente desfavorável para a evolução tecnológica. Para Malvezzi (2007) e Queiroz (2019) durante muito tempo, a maioria das políticas oficiais destinadas à região semiárida foram aquelas chamadas de "combate às secas", as quais muitas vezes estavam voltadas para grandes obras hidráulicas, controladas pela oligarquia políticoeconômica da região, pois as construções eram realizadas nas propriedades de tais pessoas, enquanto os projetos de desenvolvimento regional eram postos em segundo plano.

Segundo Castro (2001) durante períodos de longa estiagem o poder público implementava medidas paliativas, como a distribuição de água através de carros-pipa e de alimentos através das frentes de emergência, reforçando o argumento que a visão governamental considerou o combate à semiaridez, em detrimento da proposta de convivência com o semiárido. Com as experiências de fracasso de combater a seca no Nordeste brasileiro, percebeu-se que era necessário investir em tecnologias viáveis de convivência com a seca, para se alcançar melhorias sociais significativas (MARENGO; CUNHA; ALVES, 2016).

Para Malvezzi (2007), a convivência com o semiárido é um modo de vida, o que deve resultar no respeito aos saberes e à cultura local. De modo que é apropriado utilizar tecnologias e procedimentos que se adaptem ao contexto ambiental e climático, construindo processos de vivências na diversidade e harmonia entre as comunidades, seus membros e o ambiente. Possibilitando melhorias na qualidade de vida e permanência na terra, apesar das variações climáticas. Em consonância, Lima (2013) diz ser necessária uma nova forma de pensar e agir que valorize a construção de 
alternativas tecnológicas, que sejam construídas a partir do diálogo do saber técnico, da sabedoria popular, da participação das famílias envolvidas na concepção e execução das novas propostas.

As implantações dessas tecnologias sociais de convivência com o semiárido vêm trazendo uma nova visão da realidade regional, com a participação das famílias e o incentivo à organização social para assegurar a participação e democratização no desenvolvimento de projetos e obras sociais. Essa nova visão de convivência com o semiárido surge com a ruptura com o modelo tradicional, onde as perspectivas estavam voltadas para práticas insustentáveis. Portanto, novos caminhos tornam-se fundamentais para compreender novas práticas que se baseiam em prática sustentável voltada ao contexto do semiárido (QUEIROZ et al., 2016).

Com o objetivo de descentralizar a posse da água, foram elaboradas ações alternativas de convivência com o semiárido. Nessa conjuntura, surge o Programa de Formação e Mobilização Social para a convivência com o semiárido: Um Milhão de Cisternas Rurais (P1MC), que tem o propósito de buscar e recriar as práticas de controle, posse e domínio privado sobre a água e a terra (BRITO et al., 2017).

O P1MC mobiliza hoje centenas de organizações da sociedade civil, que atuam no gerenciamento e desenvolvimento de políticas de convivência com a região semiárida, sendo a sua missão promover o fortalecimento da sociedade civil na construção de processos participativos para o desenvolvimento sustentável e a convivência com o semiárido, referenciados em valores culturais e de justiça social (BRITO et al., 2017).

Este trabalho, parte da premissa que as tecnologias sociais hídricas promovem melhorias na qualidade de vida dos beneficiados. Nesse sentido, a pesquisa objetiva identificar aspectos de melhorias na vida das famílias beneficiadas com as tecnologias sociais hídricas de convivência com o semiárido na comunidade Águas Belas, localizada no Município de Nazarezinho - PB. Destarte, busca-se perceber, principalmente, avanços socioeconômicos e o estreitamento dos vínculos culturais 
dos moradores com o território/natureza mediante a implementação das cisternas de placas, das cisternas de produção e das barragens subterrâneas.

\section{METODOLOGIA}

A pesquisa engloba um estudo de caso que investiga como e em quais circunstâncias o uso de tecnologias sociais hídricas promove melhorias no contexto de vida das famílias integrantes da comunidade Águas Belas, localizada no Município de Nazarezinho - Paraíba/Brasil, distando cerca de $20 \mathrm{~km}$ da sede do município e 470 $\mathrm{km}$ da capital do Estado.

Conforme os dados de campo, a referida comunidade é composta de 25 famílias fixas, no entanto, 3 delas estão em situação específica, a qual é relativa à constante circulação em direção às cidades de Cajazeiras - PB e Marizópolis - PB, respectivamente, tais pessoas passam a maior parte do tempo nas citadas cidades, mas continuam vinculadas ao campo, principalmente através das atividades agropecuárias. Considerando a população fixa, a comunidade estudada é formada de 44 pessoas, dentre as quais crianças, adultos e idosos. É importante ressaltar que todas as famílias fixas na comunidade foram beneficiadas com algum tipo de tecnologia social de convivência com o semiárido, seja a cisterna de placas, a cisterna de produção ou a barragem subterrânea.

Em relação aos procedimentos da pesquisa foram realizados levantamentos bibliográficos, documentais e estudo de campo. No que se refere ao estudo bibliográfico foi realizada a revisão da literatura relativa ao objeto da pesquisa. A partir de buscas na internet mediante os termos "convivência com o semiárido" foram selecionados materiais em diversas bases de dados e posteriormente filtrados por meio da palavra-chave "tecnologias sociais hídricas". O estudo foi embasado principalmente nas obras de Castro (2001), Malvezzi (2007), Albuquerque Júnior (2009), Baptista e Campos (2013) e Brito et al., (2017).

No tocante ao estudo documental foram realizados, principalmente, levantamentos de dados junto a associação de moradores de Águas Belas (Nazarezinho - PB), além de

Disponível em: https://www.nucleodoconhecimento.com.br/meio-ambiente/comunidade-aguas$\underline{\text { belas }}$ 
documentos disponibilizados no sítio oficial da Articulação do Semiárido (ASA). Outro foco deste estudo foi entender o sistema de atuação dos Programas Um Milhão de Cisternas Rurais (P1MC) e Uma Terra e Duas Águas (P1+2).

O trabalho de campo se deu no reconhecimento da paisagem, onde foram registrados os principais tipos de tecnologias sociais hídricas implantadas na comunidade estudada, bem como as formas de uso das mesmas. Essas informações colhidas foram analisadas e tabuladas principalmente na forma de gráficos, os quais foram confeccionados através do Microsoft Office Excel.

\section{CONTEXTUALIZAÇÃO DO OBJETO DE ESTUDO}

Segundo Marengo et al., (2016) as secas no Semiárido nordestino acontecem desde o século XV, mas segundo Albuquerque Júnior (2009) essa situação muitas vezes é retratada de forma distorcida nos diferentes meios de comunicação, na literatura regional, no meio social, etc. Conforme Queiroz (2019) ainda na atualidade essa panaceia é transmitida de forma superficial, ou seja, a partir das consequências, deixando de lado as causas, as quais parecem não estar ligadas exclusivamente à escassez de chuvas. Essa construção ideológica da seca como fenômeno decorrente da "falta de chuvas" é contestada por Malvezzi (2007), que expõe:

É o Semiárido mais chuvoso do Planeta: a pluviosidade é, em média, $750 \mathrm{~mm} / \mathrm{ano}$ (variando, dentro da região, de $250 \mathrm{~mm} / \mathrm{ano}$ a $800 \mathrm{~mm} / \mathrm{ano}$ ). Há déficit hídrico. Mas essa expressão não significa falta de chuva ou de água. O grande problema é que a chuva que cai é menor do que a água que evapora. No Semiárido brasileiro, a evaporação é de $3.000 \mathrm{~mm} / \mathrm{ano}$, três vezes maior do que a precipitação. Logo, o jeito de agasalhar a água de chuva é fundamental para aproveitá-la (MALVEZZI, 2007, p. 10).

Malvezzi (2007) destaca que a análise mais representativa da realidade da seca no Semiárido deve abranger a falta de água no contexto das classes sociais mais carentes, isto em decorrência de uma política de privilégios implantada há muito tempo, na qual o investimento de dinheiro público esteve quase sempre em benefício das oligarquias. Para Queiroz (2019) isso demonstra que a seca no semiárido estão associadas a outros fatores, principalmente à falta de políticas públicas voltadas à

Disponível em: https://www.nucleodoconhecimento.com.br/meio-ambiente/comunidade-aguas- 
implementação da reforma agrária e, também a projeto para o armazenamento e utilização eficiente da água da chuva pela população, assim como na implantação de novas tecnologias no processo produtivo, especialmente a agricultura de subsistência.

Conforme Malvezzi (2007) e loris (2013) outro problema relacionado com a escassez hídrica está relacionada à estrutura agrária nordestina, sendo que a posse da terra se concentra nas mãos dos grandes latifundiários, que dominam o poder oligárquico da região, deixando a maioria da população à mercê do efeito climático. Percebe-se, conforme Queiroz (2019), que a escassez de recursos hídricos no nordeste brasileiro é o resultado de um processo de exploração dos recursos naturais a serviço de um desenvolvimento desigual e exclusivo implantado ao longo de sua história socioeconômica.

Segundo Queiroz et al., (2016) a cada período de estiagem milhares de pessoas que vivem nessa região não conseguem satisfazer suas necessidades básicas devido à insegurança hídrica e alimentar. O maior problema está na falta de políticas públicas que priorize projetos de captação e reutilização, evitando assim que grande parte dessa água seja desperdiçada por não ter meio adequado para o armazenamento e faltam incentivos governamentais que priorizem não tão-somente a classe dominante.

O Semiárido é composto por uma grande variedade de ecossistemas, com os seus limites e as suas potencialidades. Portanto, nessa região é possível construir ou resgatar relações de convivência entre os seres humanos e a natureza, através do tripé da sustentabilidade ambiental: qualidade de vida das famílias sertanejas, e dos incentivos às atividades econômicas adequadas às características do ambiente que provoquem rupturas com modelo tradicional, sendo que em muitos casos as perspectivas de desenvolvimento estavam voltadas para práticas insustentáveis. Desse modo, é preciso adotar um novo paradigma de desenvolvimento local e sustentável para essa região. Nessa concepção, o segredo da convivência está em compreender as características climáticas da região e adequar-se a elas. Neste aspecto, não se trata mais de combater as secas, mas sim de adaptar-se de forma 
racional. É preciso utilizar as riquezas naturais de forma a não comprometer a disponibilidades desses recursos para as futuras gerações (MALVEZZI, 2007).

É nesse sentido, que se faz necessário compreender a relação do homem com seu ambiente físico, adequando métodos e técnicas que possibilitem conviver de maneira sustentável, desenvolvendo assim as potencialidades dessa região (MARENGO; CUNHA; ALVES, 2016).

Existem muitos problemas na região Semiárida, como econômicos, ambientais e a falta de políticas públicas que facilitem seu desenvolvimento. Entre os principais problemas do Semiárido está a falta de água e terra para a maioria da população, e como também a inexistência de políticas públicas que valorizem o conhecimento sobre as condições climáticas e os ecossistemas locais (QUEIROZ, 2019).

Para promover o desenvolvimento do Semiárido numa perspectiva de justiça e equidade é fundamental conhecer os dois modelos de desenvolvimento adotados atualmente: de um lado temos um modelo baseado na concentração da terra e da água nos grandes projetos, no agronegócio, nos transgênicos e nos agrotóxicos e do outro lado aborda um modelo baseado nas inúmeras experiências locais de organização e produção, fundamentado na cultura e na tradição do povo, na matriz agroecológica, nas diversidades de formas organizativas que, criativamente, expressam modos sustentáveis de convivência nesse ambiente (MALVEZZI, 2007; BAPTISTA; CAMPOS, 2013).

Para o imperativo e possibilidade da convivência com ecossistemas frágeis é preciso um processo participativo dos indivíduos da localidade no resgate e na construção cultural de opções apropriadas aos ecossistemas. É fátuo o conhecimento das populações da localidade, somando-se aos demais conhecimentos acumulados pela humanidade acerca das ocorrências da natureza; outra necessidade é aproveitar os recursos potenciais para avanço das condições de vida dessas populações locais (CASTRO, 2001). 
Na luta pela convivência com a realidade semiárida, indivíduos e organizações vêm integrando-se para propor um novo modelo de desenvolvimento para o Nordeste. Esse modelo de desenvolvimento deve considerar a relação de convivência entre os seres humanos e a natureza, tendo em vista a melhoria da qualidade de vida das famílias. Nesse novo modelo, atribui um novo significado no ponto de vista às condições naturais e possibilitar enxergar o Semiárido com suas características próprias, sendo limites e potencialidades (CASTRO, 2001; MALVEZZI, 2007; IORIS, 2013)

Uma das propostas para adaptação às condições do semiárido é a implantação do programa de Disseminação de tecnologias apropriadas para a região, tendo por orientação a recuperação e preservação dos recursos naturais, o reordenamento dos espaços agro econômicos, a promoção de mudanças nos padrões tecnológicos e as alternativas de inserção no mercado nacional (BARACUHY, 2017).

Organizações Não-Governamentais atuantes no Semiárido e algumas organizações públicas de pesquisa e extensão no meio rural, como Empresa Brasileira de Pesquisa Agropecuária - Embrapa e Empresa Brasileira de Assistência Técnica e Extensão Rural - Emater (Atualmente nomeada Empresa Paraibana de Pesquisa, Extensão e regularização Fundiária (Empaer), passaram a cultivar propostas e a experimentar tecnologias hídricas e produtivas, apresentando alternativas apropriadas à realidade ambiental, cultural e socioeconômica do Semiárido (BRITO et al., 2017; QUEIROZ, 2019).

Estratégias foram elaboradas e trabalhadas, com o objetivo de criar alternativas de convivência com a seca e fomentar o desenvolvimento sustentável na região Nordeste, destacam-se iniciativas como o projeto Áridas e a Articulação do Semiárido (ASA). O primeiro propõe a mudança rumo do desenvolvimento, visando à redução da pobreza e melhoria da qualidade de vida dessa população, através de uma visão em que os problemas da região semiárido são considerados como problema nacional, além disso, buscam desenvolver uma ideia de desenvolvimento sustentável amplo, para atender as especificidades da região Nordeste, desde a preservação de seus 
ecossistemas, até a inserção de questões relacionadas à fome, à debilidade institucional, pobreza e à descontinuidade das políticas públicas de desenvolvimento (MIN, 2008).

Existem várias tecnologias que captam e armazenam água da chuva para a produção de alimentos, sendo estas configuradas de acordo com as características do local onde vão ser implementadas e a interação da sua utilização pelos proprietários, de modo estratégico. Atualmente, o P1+2 trabalha com as seguintes tecnologias sociais: cisterna calçadão, barragem subterrânea, tanque de pedra ou caldeirão, bomba d'água popular, barreiro-trincheira, barragem improvisada e cisterna de enxurrada (ASA BRASIL, 2019).

\section{RESULTADOS E DISCUSSÕES}

No gráfico 1 é destacado as Tecnologias Sociais hídricas implantadas nos últimos anos na Comunidade Águas Belas, Nazarezinho - PB, por meio do levantamento documental foi possível detectar na comunidade 25 cisternas de placas, 6 cisternas de produção e 4 barragens subterrâneas (Gráfico 1).

Gráfico 1 - Tecnologias Sociais hídricas implantadas na área de estudo

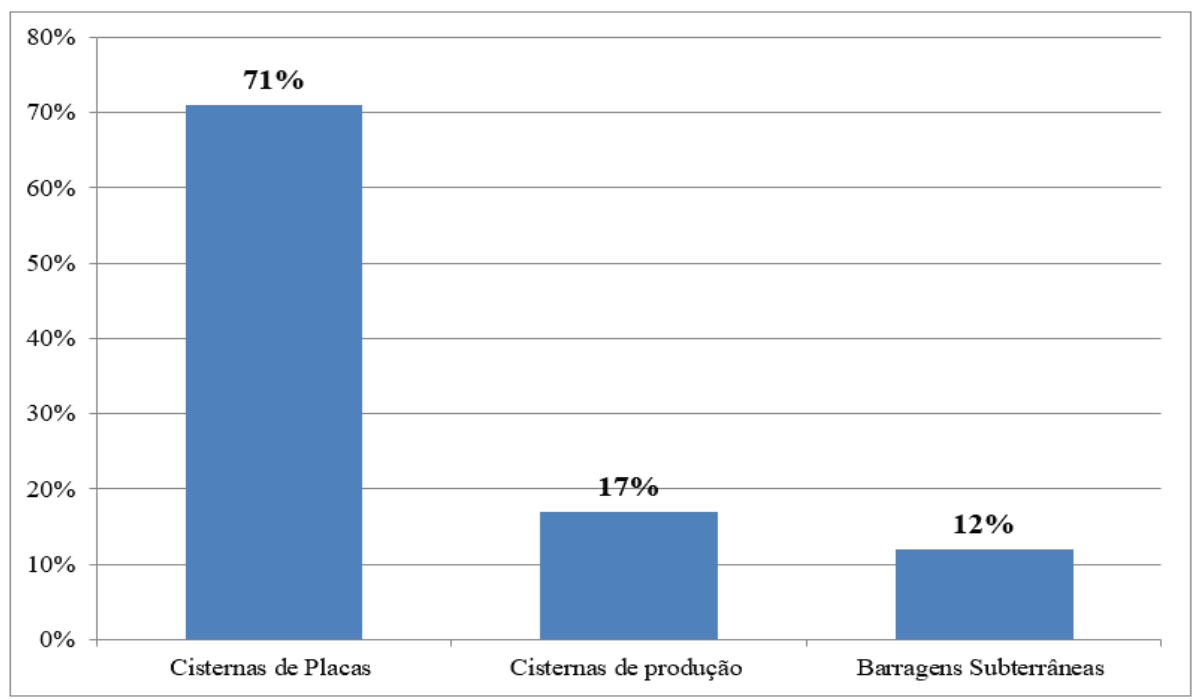

Fonte: Dados da pesquisa, 2019.

RC: 72266

Disponível em: https://www.nucleodoconhecimento.com.br/meio-ambiente/comunidade-aguasbelas 
O gráfico 1 demonstra que as cisternas de placas são as tecnologias hídricas mais representativas dentre as demais com $(71 \%)$, representando uma grande diferença em relação às cisternas de produção e às barragens subterrâneas.

A figura 01 , abaixo mostra o modelo de cisterna encontrado na comunidade, destacase que cada uma das 25 famílias possuem algum tipo de cisterna para suprir suas necessidades básicas.

Figura 1: Cisterna de uma residência na comunidade Águas Belas, Nazarezinho - PB

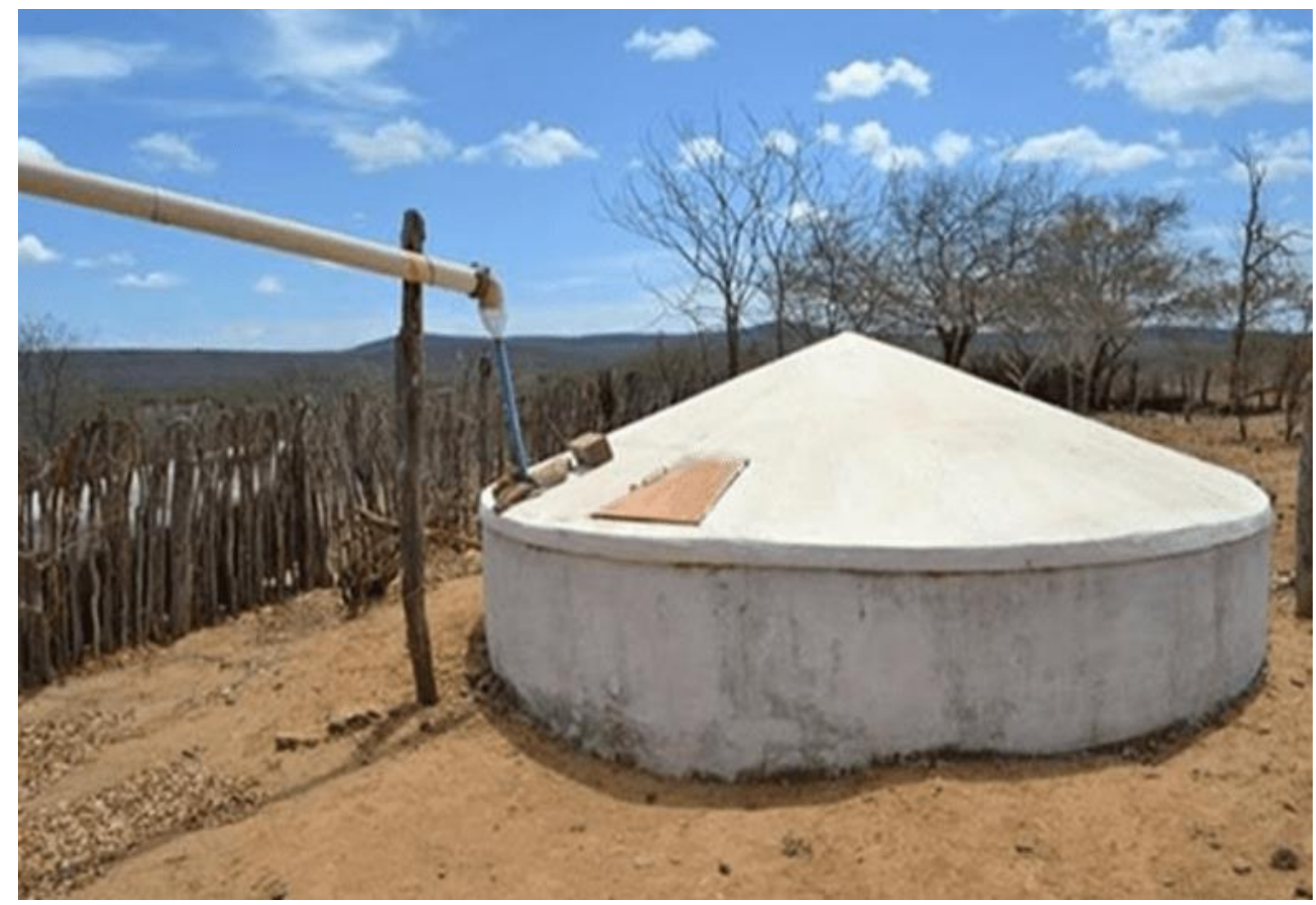

Fonte: Dados da pesquisa, 2019.

Para Malvezzi (2007) as famílias utilizam as cisternas para armazenar a água das chuvas no período do inverno para beber durante o período de estiagem. O importante dessa tecnologia é a garantia de água limpa para consumo humano. As principais vantagens dessa tecnologia é o baixo custo, a redução considerável dos desperdícios 
e a baixa incidência de agressão ao meio ambiente. No que se refere às cisternas de produção e as barragens subterrâneas. Brito et al., (2017) enfatizam que essas tecnologias ainda são pouco utilizadas por serem recursos pouco conhecidos pela população e com altos custos de implantação, se comparada a outras tecnologias. É importante ressaltar que na comunidade estudada as mencionadas tecnologias foram custeadas integralmente pelas próprias famílias.

Abaixo destaca-se outro tipo de cisterna encontrada na comunidade.

Figura 2: Cisterna do tipo calçadão na comunidade Águas Belas, Nazarezinho - PB.

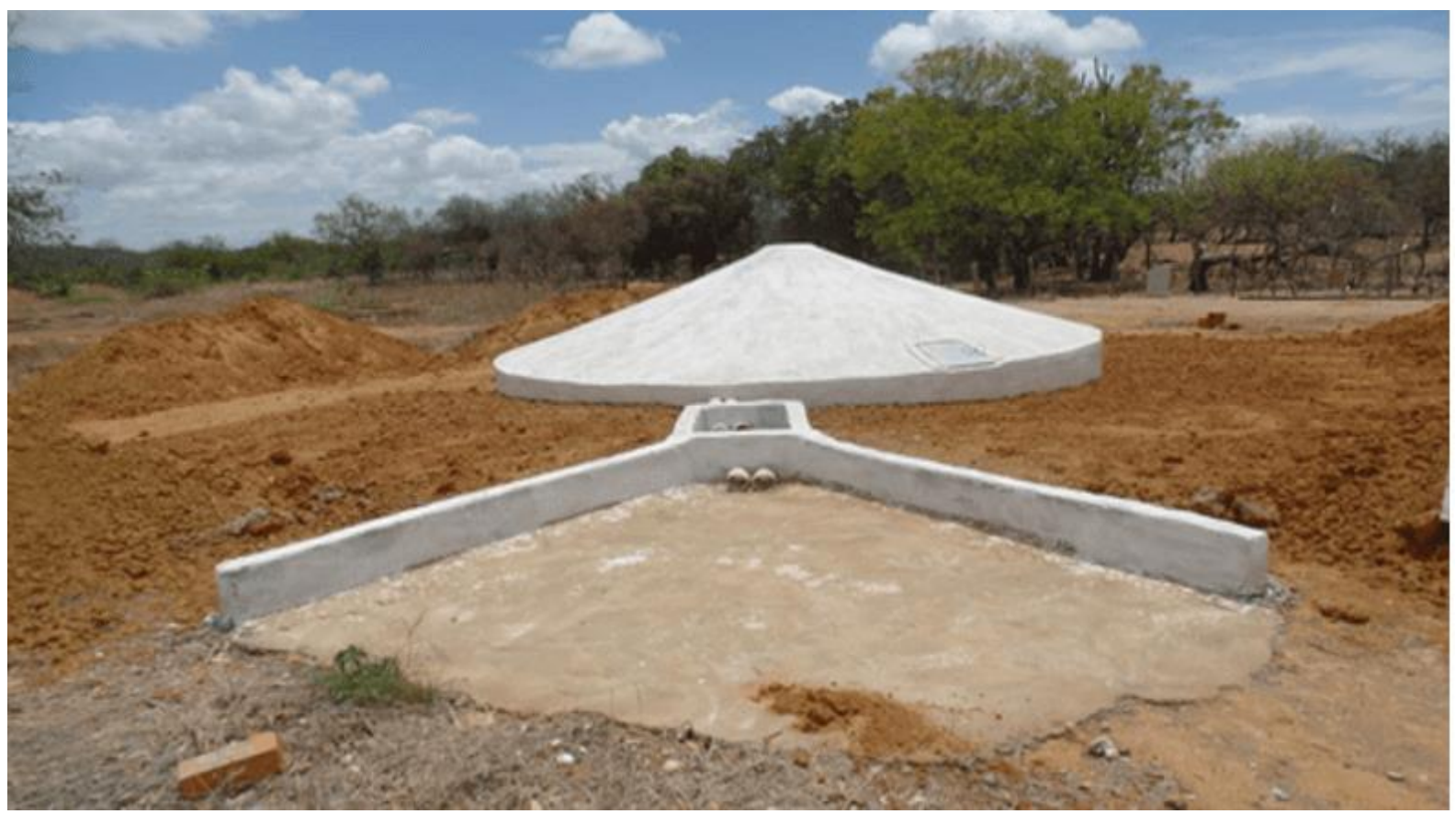

Fonte: Dados da pesquisa, 2019.

De acordo com Baracuhy (2017) a cisterna calçadão é construída no nível do solo, onde capta água da chuva que escoa para a cisterna. Sua capacidade de armazenamento como já foi mencionada anteriormente é de 52 mil litros de água. Essa água é usada para produzir alimentos através da irrigação de frutíferas e hortaliças no entorno das residências para criação de animais. Esta simples solução aperfeiçoa a captação de água da chuva para favorecer a segurança nutricional e

Disponível em: https://www.nucleodoconhecimento.com.br/meio-ambiente/comunidade-aguas$\underline{\text { belas }}$ 
alimentar (DIACONIA, 2008). Porém, considerando a segurança hídrica humana, muitos desses modelos podem "povoar" a propriedade, dando autonomia plena de água e uma melhor qualidade para produções pequenas e para as pessoas.

As cisternas produtivas e as barragens subterrâneas armazenam a água que serve para complementar as atividades produtivas desenvolvidas no meio rural na região semiárida, que quase sempre são ligadas à agricultura de subsistência e à pequena pecuária. Por meio dessas atividades os sertanejos buscam complementar o sustento de suas famílias (MALVEZZI, 2007), realidade inerente à área de estudo.

Nessa mesma direção, durante o levantamento acerca das principais atividades produtivas praticadas na Comunidade Águas Belas, o destaque ficou para agricultura de subsistência, bovinocultura, caprinocultura ou ovinocultura (Gráfico 2).

Gráfico 2 - Principais Atividades agrícolas implantadas na área de estudo.

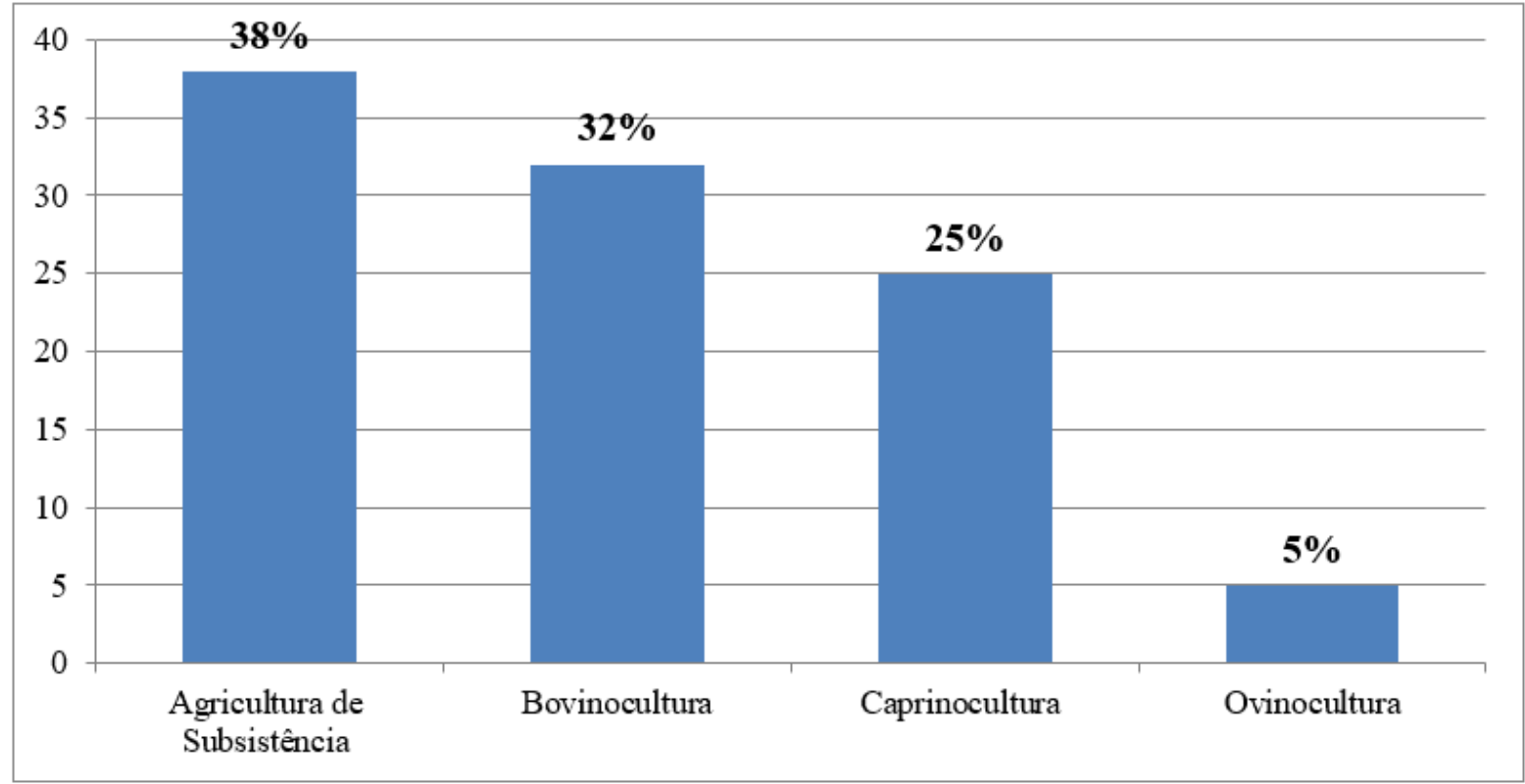

Fonte: Dados da pesquisa, 2019.

É possível constatar no gráfico 2, que a agricultura de subsistência se destaca dentre as principais atividades produtivas praticadas na comunidade Águas Belas. A referida

Disponível em: https://www.nucleodoconhecimento.com.br/meio-ambiente/comunidade-aguasbelas 
cultura faz parte da identidade local, sendo passada de forma hereditária, além disso, a mecanização é baixa ou inexistente como mostra a figura 02 logo abaixo.

Figura 3: Plantação de Coentro e Batata doce na comunidade Águas Belas, Nazarezinho - PB.

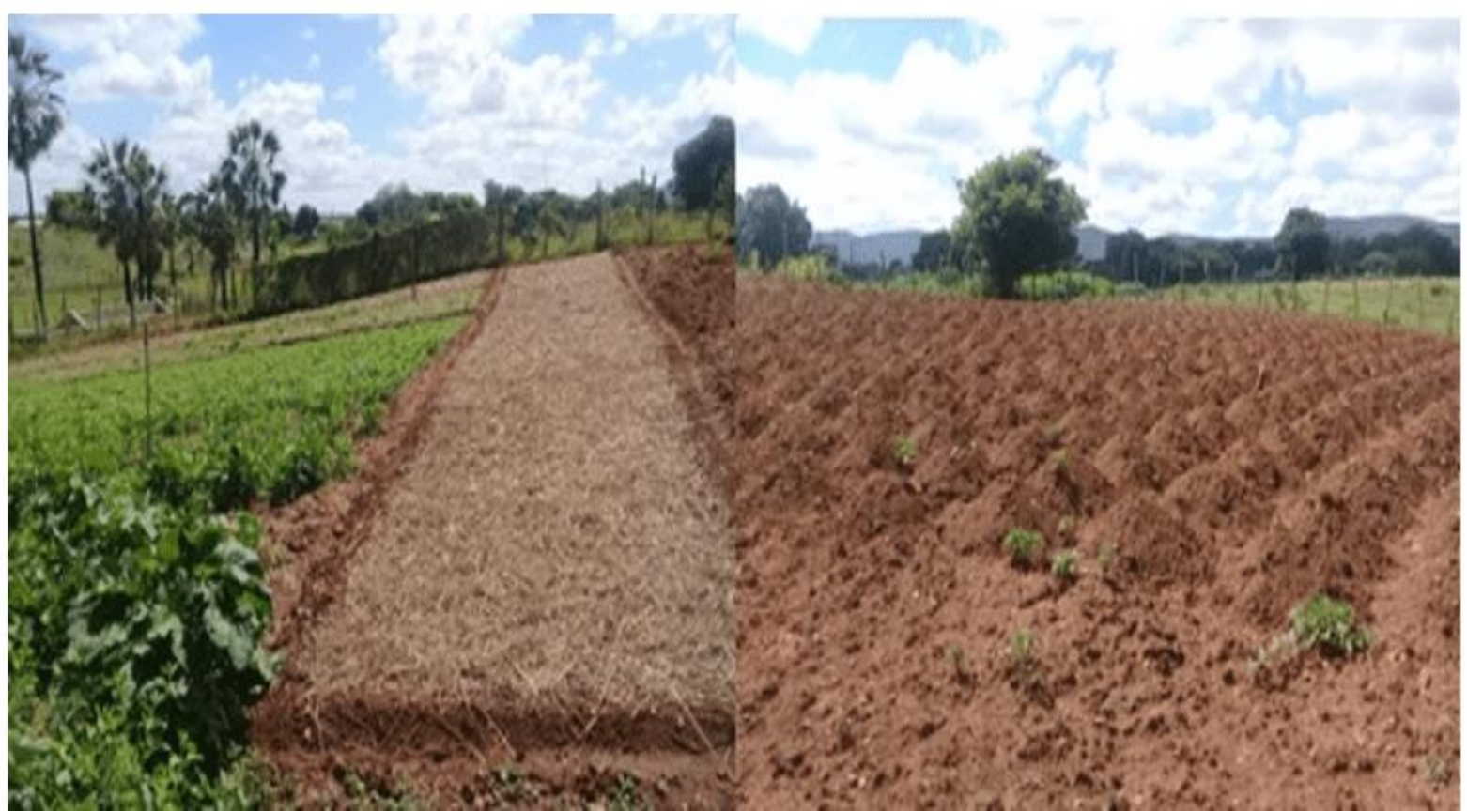

Fonte: Dados da pesquisa, 2019.

A água utilizada para irrigar a terra é proveniente da chuva e armazenada em cisterna com capacidade para 50 mil $L$, e corresponde à segunda água na definição do P1+2. A produção de frutas e hortaliças tem por objetivo diversificar e melhorar a qualidade da alimentação das famílias rurais, e o excedente ser comercializado no comércio local, gerando assim uma renda fixa para as famílias dos agricultores, como também criar empregos e renda para as comunidades envolvidas nessa área.

Ainda, conforme o gráfico acima, a pecuária também se destaca na localidade, principalmente em relação à criação de gado bovino. Nesse caso, a bovinocultura pauta-se principalmente na produção de leite de vaca para o consumo próprio das famílias ou para a comercialização local.

Disponível em: https://www.nucleodoconhecimento.com.br/meio-ambiente/comunidade-aguasbelas 
A criação de bovinos, caprinos e ovinos no semiárido brasileiro tem-se consolidado nas últimas décadas como uma importante atividade de produção animal para a subsistência, constituindo-se como atividade de extrema importância (BARBOSA; XAVIER, 2018). Nesse contexto, segundo Batista (2015), a criação de animais gera uma fonte de renda para pequenos produtores, seja no contexto sociocultural, pela fixação do homem ao campo e perpetuação da atividade produtiva.

A figura 4 abaixo, mostra a criação do rebanho nas pequenas propriedades na comunidade de Águas Belas.

Figura 4: Plantação Criação de Animais na comunidade Águas Belas, Nazarezinho PB.

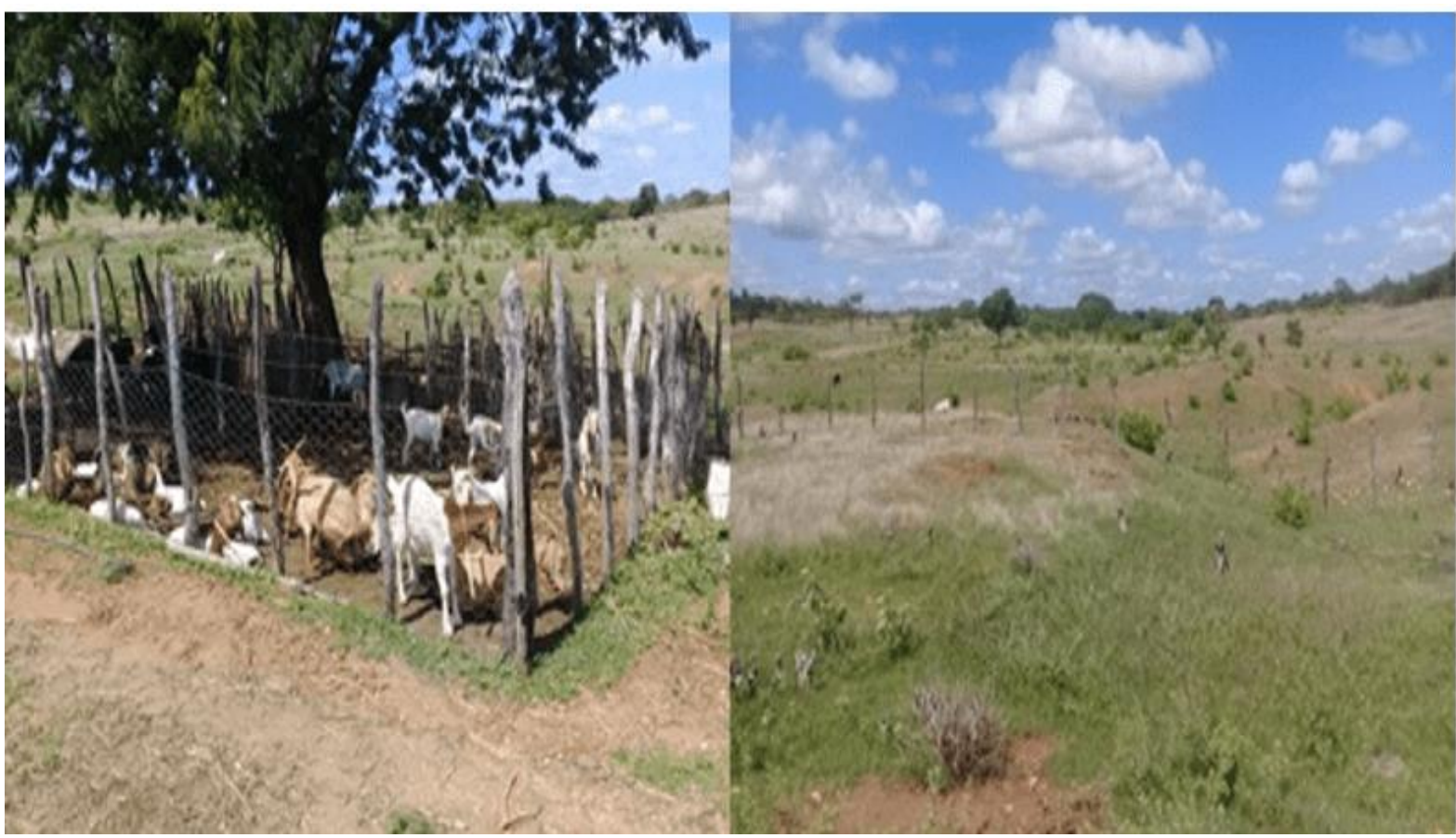

Fonte: Dados da pesquisa, 2019.

A caprinocultura também se destaca na comunidade estudada, sendo que os produtores criam os animais e muitas vezes vendem no local ou nas feiras livres das cidades vizinhas, cujo dinheiro serve para o custeio de despesas de suas famílias, a exemplo da alimentação e do vestuário. Essa mesma dinâmica ocorre em tempos de

Disponível em: https://www.nucleodoconhecimento.com.br/meio-ambiente/comunidade-aguas$\underline{\text { belas }}$ 
estiagens prolongadas, no entanto, é uma atividade muito importante, tanto pelo aspecto econômico, na geração de renda, quanto pela inclusão social.

Essa realidade produtiva reflete as palavras de Malvezzi (2007) quando diz que a criação de gado no Nordeste brasileiro, de modo amplo, é realizada por agricultores familiares, sendo desenvolvida com baixo padrão tecnológico e produção inconstante, devido à influência das estiagens mais demoradas e intensas.

$\mathrm{Na}$ pesquisa junto a associação de moradores foi possível detectar as possíveis mudanças socioeconômicas ocorridas a partir da implantação das tecnologias hídricas quanto à geração de renda, à segurança hídrica e alimentar e à saúde.

Isso se deu, sobretudo, à disponibilidade de reservatórios apropriados para armazenar a água das chuvas, as cisternas de placas. Segundo Baptista e Campos (2013) essa água tem elevados padrões de qualidade, pois dificilmente entra em contato com microrganismos ou substâncias que alteram a potabilidade, assim favorecendo a não ocorrência ou a redução significativa de doenças veiculadas ao referido recurso.

Ainda em relação no que se refere à segurança alimentar percebe-se que esse aspecto também é significativamente representativo. Logo, são 10 estruturas hídricas construídas na comunidade (6 cisternas produtivas e 4 barragens subterrâneas), cuja finalidade principal é a produção de alimentos, os quais complementam a nutrição das famílias, e o excedente representa fonte de renda mediante a comercialização das frutas legumes e hortaliças.

Este contexto reflete as palavras de Malvezzi (2007) e Baptista e Campos (2013) e Brito et al., (2017), o qual representa melhorias quanto ao acesso à água por parte das populações beneficiadas pelas tecnologias sociais hídricas, bem como o desenvolvimento de algumas culturas agrárias. As transformações sociais, econômicas e ambientais que essas tecnologias vêm proporcionando estão na direção do desenvolvimento sustentável e do fomento de condições incentivadoras da permanência das famílias no campo. 
Para compreender os principais desafios enfrentados no processo de convivência com o semiárido, Ab'Sáber (2006) e Queiroz (2019) ressaltam que estamos no Semiárido mais chuvoso do mundo, sendo que as irregularidades espaço-temporais quanto a distribuição das precipitações são características típicas do clima. Para Malvezzi (2007) e Silva et al., (2015) a escassez hídrica é provocada muito mais por aspectos políticos (concentração da terra e da água, dentre outros) do que fatores naturais.

Outra questão importante disposta, diz respeito à falta de investimento por parte do poder público em novas tecnologias hídricas de captação e armazenamento de água complementar. Na verdade, essa ainda é uma das principais limitações dos governos. Nesse prisma, segundo Malvezzi (2007) o que falta mesmo no Semiárido é o desenvolvimento de políticas públicas voltadas à captação e ao armazenamento da maior quantidade possível de água para suprir a necessidade humana e animal nos períodos de estiagem, os quais geralmente duram entre cinco e 6 meses do ano, ou seja, é preciso gerenciar melhor a água.

Os resultados também expõem uma das questões mais delicadas relativas às tecnologias hídricas, a qual se refere à ausência de assistência técnica após a implantação das referidas estruturas de captação e armazenamento de água. Dessa forma, os agricultores ficam responsáveis por todos os processos de manutenção dessas estruturas. Para Silva et al., (2015) e Queiroz et al., (2016) essa é uma das principais limitações do $\mathrm{P} 1 \mathrm{MC}$ e do $\mathrm{P} 1+2$, haja vista, na maioria dos casos as famílias não dispõem de condições para realizar tais serviços.

Os resultados evidenciam a importância das tecnologias sociais hídricas, principalmente as cisternas de placas, que auxiliam na melhoria da qualidade de vida dos moradores da comunidade Águas Belas, à medida que favoreceu permanência desses sertanejos no campo e melhorou tanto na reprodução socioeconômica, quanto na saúde dos membros das famílias que sofriam com doenças provocadas pelo uso de água imprópria para o consumo. 


\section{CONSIDERAÇÕES FINAIS}

A implantação das tecnologias de convivência com 0 semiárido, àquelas principalmente relativas à captação e armazenamento de água, vêm possibilitando a melhoria das condições de vida das famílias da comunidade Águas Belas. Isto principalmente na democratização do acesso à água, ao consumo de água de qualidade, e à produção de alimentos, com a comercialização inclusive de excedentes na localidade e na feira livre da cidade de Cajazeiras - PB. Assim, essas tecnologias são muito representativas no campo da segurança hídrica e alimentar.

Com pouco tempo de implantação de tais tecnologias o cenário mostra-se transformado favoravelmente. As populações que antes passavam por grandes dificuldades devido à falta de água hoje desfrutam dos benefícios de ter água nos pés de suas casas e de poder produzir alimentos a partir do recurso hídrico acumulado em cisternas de produção e barragens subterrâneas.

Portanto, a pesquisa demonstra que houve melhoras na qualidade de vida das famílias residentes na comunidade Águas Belas. Por fim, este estudo também demonstra mudanças positivas das ações políticas governamentais em relação às novas abordagens frente à necessidade de convivência com o semiárido.

\section{REFERÊNCIAS}

AB'SÁBER, A. N. A transposição de águas do São Francisco: análise crítica. Revista USP, São Paulo, v. 1, n. 70, p. 6-13, 2006.

ALBUQUERQUE JÚNIOR. D. M. de. A invenção do Nordeste e outras artes. 4a ${ }^{\mathrm{a}}$. ed. Recife: FJN; Ed. Rev. e atual. Massangana; São Paulo: Cortez, 2009, 340p.

ASA BRASIL. Articulação do Semiárido Brasileiro - ASA. Ações: P1+2. Disponível em: http://www.asabrasil.org.br/acoes/p1-2\#categoria_img. 01 de junho de 2019. 
ASA BRASIL. Articulação do Semiárido Brasileiro - ASA. Ações: P1MC. Disponível em: http://www.asabrasil.org.br/acoes/p1mc. 01 de junho de 2019.

ASA BRASIL. Articulação do Semiárido Brasileiro - ASA. É no semiárido que a vida pulsa! Disponível em: http://www.asabrasil/semiarido. 01 de junho de 2019.

ASA BRASIL. Articulação do Semiárido Brasileiro - ASA. Programa Uma Terra e Duas Águas. Disponível em: http://www.asabrasil.org.br/acoes/p1-2. 01 de junho de 2019.

ASA BRASIL. Articulação do Semiárido Brasileiro - ASA. Tecnologias Sociais para a Convivência com o Semiárido - Série Estocagem de Água para Produção de Alimentos: Cisterna Calçadão. 10ª . ed. Recife: Asa, 2014.

BAPTISTA, N. Q.; CAMPOS, C. H. Caracterização do semiárido brasileiro. In: Conti, I. L.; Schroeder, E. O. (Org.). Convivência com o Semiárido Brasileiro: Autonomia

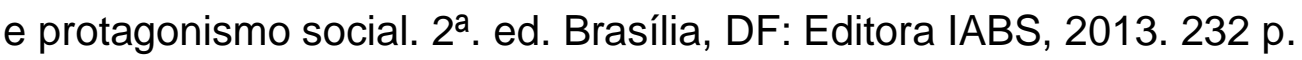

BARBOSA, R. F.; XAVIER, R. A. Diagnóstico da caprinovinocultura no Cariri Ocidental da Paraíba (PB): estudo de caso de 2005 a 2015. Revista Ibero-Americana de Ciências Ambientais, v. 9 n. 8, 2018.

BARACUHY, J. G. de V. Tecnologia de convivência com o semiárido brasileiro. Campina Grande: EDUFCG, p. 49-51, 2017

BRITO, F. C. S.; LIMA, D. C.; SOUZA, J. D.; MEDEIROS, A. C.; MARACAJA, P. B.; MEDEIROS, A. P.; PAIVA, A. C. C. Uma abordagem histórica e teórica das políticas públicas de combate à seca e convivência com o semi-árido. Revista Brasileira de Gestão Ambiental, v. 11, p. 57-65, 2017.

CASTRO, I. E. de. Natureza, imaginário e a reinvenção do Nordeste. In ROSENDAHL, Zeny et CORRÊA, Roberto Lobato (orgs.) Paisagem, imaginário e espaço. Rio de Janeiro: EdUERJ, 2001. 
DIACONIA, A. Convivendo com o semiárido: manejo de recursos hídricos. Série Compartilhando Experiências, Brochura, n. 1, 2003.

IORIS, A. A. R. Na contracorrente dos Recursos Hídricos - água e ambiente no Brasil contemporâneo. Edimburgo, 2013, 183 p.

IPCC. Intergovernmental Painel on Climate Chang. IPCC Fourh Assessment Report, Climate 2007. Working Group III: Mltigation of Climete Chang Disponivel em: http://www.ipcc.ch/publications_and_data_report.shml Acesso em: 01 de junho de 2019.

LIMA, A. O. Nova abordagem metodológica para ligação, modelagem 3D e monitoramento de barragens subterrâneas no Semiárido Brasileiro. Tese de Doutorado (Geodinâmica e Geofísica) - Centro de Ciências Extas e da Terra, Programa de Pós-Graduação em Geodinâmica e Geofísica, Universidade Federal do Rio Grande do Norte, Natal, 2013.

MALVAZZI, R. Semiárido: uma visão holística. Brasília, DF: Pensar Brasil, 2007. $140 \mathrm{p}$.

MARENGO, J. A.; CUNHA, A. P.; ALVES, L. M. A seca de 2012-2015 no semiárido do Nordeste do Brasil no contexto histórico. Centro Nacional de Monitoramento e Alertas de Desastres Naturais (CEMADEN), São Paulo, Brasil, 2 Centro de Ciências do Sistema Terrestre - Instituto Nacional de Pesquisas Espaciais (CCST/INPE), São Paulo, Brasil, 2016.

MIN. Ministério da Integração Nacional. Projeto Áridas: memória e acervo. Instituto Interamericano de Cooperação Para a Agricultura - IICA. 2008. Disponível em: http://bibliotecadigital.planejamento.gov.br/handle/iditem/678. Acesso em: 01 de junho de 2019.

QUEIROZ, J. G. Os vieses da questão hidrossocial e os penduricalhos produtivos do perímetro irrigado de São Gonçalo - Paraíba: quais os arranhões e as ferrugens que 
o desgastaram durante o período de 2012 a 2017? Dissertação Mestrado (Planejamento e Dinâmicas Territoriais no Semiárido) - Universidade do Estado do Rio Grande do Norte - UERN, Pau dos Ferros, 2019.

QUEIROZ, J. G.; SILVA, O. R.; SÁ, R. M. Cisternas, barragens subterrâneas e bomba popular: convivência com as secas no Sítio Logradouro dos Alves/Sousa - PB, um estudo de caso. $1^{\circ}$ Encontro Nacional de Planejamento Urbano e Regional no Semiárido. Natal: CCHLA, 2016, p. 39-54.

SCHENEIDER, S. A. Abordagem territorial do desenvolvimento rural e suas articulações externas. Sociologias, v. 6, n. 11, p. 88-125, 2004.

SILVA, J. B; GUERRA, L. D.; IORIS, A. GOMES, R. A. Conflitos sociopolíticos, recursos hídricos e programa um milhão de cisternas na região semiárida da Paraíba. Novos Cadernos NAEA, Guamá, v. 18, n. 2, p. 69-92, 2015.

Enviado: Outubro, 2020.

Aprovado: Janeiro, 2021. 